\title{
A Small and Medium Enterprise Financing Efficiency Analyzing Method based on an Improved DEA Model
}

\author{
Yuan Feng*
}

School of Economics, Shandong University, Jinan, Shandong 250100, China

\begin{abstract}
As the efficiency measuring and analyzing is a crucial problem in modern enterprise management, this paper focuses on the problem of small and medium enterprise financing efficiency analyzing, and we proposed an improved DEA model based on stepwise regression to tackle this problem. Data envelopment analysis technology can calculate the efficiency of each decision making unit relative. Hence, DEA can provide an efficient frontier or envelop for all considered decision making units rather than fitting a regression plane through the center of the data. To solve the limitations in traditional DEA model, we propose an improved DEA model using the stepwise regression technology which has the ability to automatically select variables for the DEA model. To test the effectiveness of our proposed DEA model, 120 small and medium enterprises of China in 2010-2013 is chosen to construct a dataset, and this dataset are collected from the annual reports of sample firms. In particular, in this experiment, the input indexes we used are (1) Total assets of an enterprise, (2) Main business cost, (3) Asset liability ratio. On the other hand, the output indexes are (1) Rate of return on net assets, (2) Main business income, and (3) Total assets turnover. Combining all the experimental results, some suggestions to enhance the small and medium-sized enterprise financing efficiency in China are offered.
\end{abstract}

Keywords: Data envelopment analysis (DEA), decision making unit, financing efficiency, small and medium enterprise, stepwise regression.

\section{INTRODUCTION}

Small and medium enterprise plays a very important role in the development of national economy. However, there are several problems in the development of small and medium enterprise [1]. Hence, it is of great importance to tackle the financial difficulties of small and medium enterprises and then let the small and medium enterprises to rapidly growth. Particularly, how to effectively solve the financing dilemma, eliminate financing barriers and enhance financing efficiency is a new topic which the whole society should face and solve $[2,3]$. As is well known that Funding is a key part for any business survival and development, and it is a key driving force for small and medium enterprise [4]. Furthermore, the financing process may cover the entire process of enterprise operation and development. Financing process is composed of both the integration of capital and capital utilization.

In order to provide useful guidances for small and medium enterprise, there are four important problems we should face, that is, 1) how to establish a reasonable financing size and structure, 2) how to develop the best financing policy, 3) how to reduce financing cost and risk, and 4) how to promote financing efficiency $[5,6]$. In recent years, more and more attentions have been paid for small and medium enterprise to enhance the credit and the service quality, and then the financing efficiency of it could be promoted [7].
Data Envelopment Analysis (DEA) refers to a nonparametric approach to estimating system efficiency, which exploits the tools of mathematical programming, that is, linear programming [8]. Data envelopment analysis is firstly designed to estimate the efficiency of a decision making unit as a whole unit, without requiring the internal structure [9]. Particularly, the system is regarded as a black box. The aim of data envelopment analysis is the division of observed subjects into efficient and inefficient objects on the basis of the size of consumed inputs, and the quantity of the outputs [10].

The rest of this paper is organized as follows. The next section gives the related literature about the application of the Data Envelopment Analysis model. Section 3 provides the statement of the efficiency measuring and analyzing problem. In section 4, the improved DEA model is presented. Performance evaluation is conducted in section 5, and the conclusions are illustrated in the final section.

\section{RELATED WORKS}

Data envelopment analysis can estimate the efficiency of each decision making unit relative to other similar ones. Therefore, DEA gives an efficient frontier or envelop for all considered decision making units rather than fitting a regression plane through the center of the data. Currently, data envelopment analysis has been applied to a variety of research areas. In this section, we will introduce the related works about the applications of data envelopment analysis.

Tueselmann et al. used the DEA technology to assess research outputs published in journals. This paper consolidates 
existing journal rankings exploiting random forests and data envelopment analysis [11].

Jain et al. studied on weight restrictions in data envelopment analysis. Particularly, this paper proposed a genetic algorithm based method for weight restrictions to combine dual role factor and organizational hierarchy in decisionmaking. There are two main innovations in this paper, 1) the proposed method involves finding a set of weights which are at a minimum distance from all the decision making preferences. 2) this method is flexible and can produce a common set of weights and decision making unit specific weight restrictions at the same time [12].

Kaveh et al. proposed a customized data envelopment analysis approach to tackle the return to scale problem in the presence of uncertain data. Note that, the uncertainty of the inputs and outputs are modeled with interval data and the emissions are supposed to be undesirable outputs. Particularly, this modified DEA model can estimate the interval efficiency scores of the DMUs and then provide an effective benchmark to promote the efficiency scores [13].

Fang et al. aimed to solve the cost efficiency problem in data envelopment analysis. In this paper, this paper proposed a pair of 2-level mathematical programming models to compute the upper and lower bounds of cost efficiency for each firm in the case of non-unique LoOP prices when keeping the industry cost efficiency optimal [14].

In paper [15], Pelone et al. put forward a systematic literature review on PC efficiency analysis with the Data Envelopment Analysis technology. The authors have reviewed 39 DEA applications in PC, to investigate how methodological frameworks affect results and influence the information for decision makers.

Banker investigated the sensitivity and stability for Banker's model of Stochastic Data Envelopment Analysis. In particular, in the DEA model, the authors utilize necessary and sufficient conditions to enhance the efficiency of efficient decision-making units and the inefficiency of inefficient decision making units are collected for different perturbations of data in the proposed DEA model [16].

Different from the above papers, Ustun et al. exploited the data envelopment analysis technology to compute the relative efficiency of disaster relief organizations which participated in the relief activities in Turkey at 1999. In particular, the unbounded data envelopment analysis model is utilized to calculate the efficiency scores and optimal inputoutput weights of the decision-making units in these groups [17].

Apart from the above proposed works, DEA model have been applied in many other applications, such as performance assessment of electricity distribution companies [18], Energy Efficiency Hierarchy Evaluation in a Petrochemical Process [19], Health care [20], measuring sustainability of industrial parks [21], Marginal rates of substitution in the presence of non-discretionary factors [22], evaluating decision-making units with fixed-sum outputs [23].

In this paper, we propose a novel modified DEA model, and use it in the problem of small and medium enterprise financing efficiency analyzing

\section{STATEMENT OF THE EFFICIENCY MEASURING AND ANALYZING PROBLEM}

The efficiency measuring and analyzing is a crucial problem in modern enterprise management, and in this section we will describe this problem in detail.

Supposing that $X_{i j}$ and $Y_{r j}$ refer to the $i^{\text {th }}$ input, $r^{\text {th }}$ output and the $j^{\text {th }}$ decision making unit. The DEA model is designed to evaluate the efficiency of a decision making unit as follows.

$E_{0}=\max \sum_{r=1}^{s} u_{r} \cdot Y_{r 0}$

Subject to

1) $\sum_{i=1}^{m} v_{i} \cdot X_{i 0}=1$

2) $\sum_{r=1}^{s} u_{r} \cdot Y_{r j}-\sum_{i=1}^{m} v_{i} \cdot X_{i j} \leq 0$

where conditions $\quad j \in\{1,2, \cdots, n\}, r \in\{1,2, \cdots, \mathrm{s}\}$, $i \in\{1,2, \cdots, \mathrm{m}\}$, and $u_{r}, v_{i} \geq \gamma$ are satisfied, and $u_{r}, v_{i}$ denote the virtual multipliers and parameter $\gamma$ means a nonarchimedean number. In the DEA model, if the returns to scale to be changed is also named as BCC model, which can be described as follows.

$E_{0}=\min \delta-\gamma \cdot\left(\sum_{i=1}^{m} s_{i}^{-}+\sum_{r=1}^{s} s_{r}^{+}\right)$

Subject to

1) $\sum_{j=1}^{n} \lambda_{j} \cdot X_{i j}+s_{i}^{-}=\delta \cdot X_{i 0}, i \in\{1,2, \cdots, m\}$

2) $\sum_{j=1}^{n} \lambda_{j} \cdot Y_{r j}-s_{r}^{+}=Y_{r 0}, r \in\{1,2, \cdots, \mathrm{s}\}$

where parameter $\lambda_{j}, s_{i}^{-}$and $s_{r}^{+}$are all larger than zero.

Different from the above model, another method to evaluate the system efficiency aims to pursue the multipliers $u, v, w$, on the other hand, the maximum efficiency $\vec{w}$ is not higher than the input of all processes, and the following conditions are satisfied.

$$
E_{0}^{S}=\max \frac{\sum_{r=1}^{s} u_{r} \cdot Y_{r 0}}{\sum_{i=1}^{m} v i \cdot X_{i 0}}
$$

Subject to

$$
\begin{aligned}
& \sum_{r \in O^{(k)}} u_{r}^{(k)} \cdot Y_{r j}^{(k)}+\sum_{g \in N^{(k)}} \vec{w}_{g}^{(k)} \cdot Z_{g j}^{(k)}- \\
& \sum_{i \in I^{(k)}} v_{i}^{(k)} \cdot X_{i j}^{(k)}-\sum_{f \in M^{(k)}} w_{f}^{(k)} \cdot Z_{f j}^{(k)} \leq 0
\end{aligned}
$$


where the symbol $k$ denotes a process, and $u_{r}^{(k)}, \vec{w}_{g}^{(k)}, v_{i}^{(k)}, w_{f}^{(k)}$ are larger than zero, and element $r, i, f, g$ are belonged to $O^{(k)}, \mathrm{I}^{(k)}, \mathrm{M}^{(k)}, \mathrm{N}^{(k)}$ respectively. By analyzing the system efficiency problem in this section, we will introduce how to improve the traditional DEA model to make it be suitable to use in small and medium enterprises financing efficiency analyzing.

\section{THE IMPROVED DEA MODEL}

Traditional DEA model supposes that decision making units are evaluated individually, hence, there are several problems in the traditional DEA model should be tackled. For example, as the former DEA model concentrates on individual decision making units, the weights of different units should be estimated accurately.

Assuming that there are a set of $n$ homogenous decision making units, that is, $D M U_{j}, j \in\{1,2, \cdots, n\}$. In particular, $X_{j}=\left(x_{1 j}, x_{2 j}, \cdots, x_{m j}\right)$ and $Y_{j}=\left(y_{1 j}, \mathrm{y}_{2 j}, \cdots, y_{m j}\right)$ refer to the vectors of input and output values for the $j^{\text {th }}$ decision making unit.

As the performance of the DEA model highly relies on the selection of input and output variables, and there is no standard process in DEA to choose a set of input and output variables. Hence, in this section, we propose an improved DEA model utilizing the stepwise regression technology that can automatically select variables for the DEA model. Stepwise regression [24] refers to a routine statistic method used for variable choosing. Particularly, stepwise regression can fit much better in sample than it does on new out of sample data. Generally speaking, in a calibration model, some input variables do not require an important explanatory influence on the output variables. Hence, it can be seen that stepwise regression approach means a combination of forward and backward processes.

Supposing that there is a data matrix $Z$ with $n$ rows and $p+q$ columns, in which each row is corresponding to an observation value and each column is related to a variable. Then, the multiple regression can be calculated of each variable in the set $Y$, in which at least $q$ elements are contained. On the other hand, we use $X$ to represent the submatrix which is measured from their respective averages for the $n$ observations.

We regard the total set of the matrix $Z$ as partitioned to two sets, that is, $X$ and $Y$, and then calculate all the results for multiple regressions to construct a matrix $R$ as follows.

$$
R=\left[\begin{array}{cc}
\left(X^{T} X\right)^{-1} & \left(X^{T} X\right)^{-1}\left(X^{T} Y\right) \\
Y^{T} X\left(X^{T} X\right)^{-1} & Y^{T} Y-Y^{T} X\left(X^{T} X\right)^{-1} X^{T} Y
\end{array}\right]
$$

where $X$ denotes the set of provisorily chosen variables, and $Y$ means the rest of $Z$. In the stepwise regression process, we should search the predictor $X_{i}$ in advance, which is s most correlated with the variable $Y$. Afterwards, based on the above definition, an improved DEA model using stepwise regression is illustrated as follows.

Algorithm 1: The improved DEA model based on stepwise regression.

1) Executing a single DEA algorithm on a set of provisorily chosen set $X$ and $Y$

2) Saving the efficiency values for the set of decision making units using a matrix with $n$ rows and $p+q$ columns (denoted as $Z=[X, Y]$ )

3) Implementing a single DEA model for a set of multiple regression using Eq.9

4) Choosing independent variables for the decision making units of the set $X$

5) Choosing the dependent variables for the set $Y$

6) Exploiting the Kruskal-Wallis test statistics for the elements in matrix $Z$, which is ranked by the DEA stepwise regression algorithm

7) If the Kruskal-Wallis test demonstrates that there still exists significance difference

8) Then testing the pair-wise significance utilizing the Conover-Inman procedure

9) End if

In algorithm 1, the Kruskal-Wallis test is implemented based the above $H$ statistics as follows.

$H=\frac{12}{n(n+1)} \cdot \sum \frac{R_{i}^{2}}{n_{i}}-3(n+1)$

where the symbol $R_{i}$ means the total number of the $i^{\text {th }}$ group, $n_{i}$ refers to the scale of the $i^{\text {th }}$ group.

\section{EXPERIMENT}

To make performance evaluation, we choose 120 small and medium enterprises of China in 2010-2013 to construct a dataset. The dataset are collected from the annual reports of sample Firms, including its year-end balance sheet, index in the profit statement. Particularly, in this paper, we delete ST shares enterprises, because these enterprises have abnormal financial status. In addition, we utilize the Global Industry Classification Standard to classify industries. Furthermore, in our proposed dataset, there are 26 basic material industries, 56 consumer non-essential industries, 17 consumers commonly used industries, 17 information technology industries, and 4 public utilities industries.

As we use the DEA model to analyze the enterprise financing efficiency, the number of samples required should be set at least two times the number of input/output index according to the experience of DMU. Therefore, the number of DMU samples is set to be 120 and the number of input/output index is six. All these settings are consistent with 
Table 1. Statistic distribution for the original data of input index.

\begin{tabular}{|c|c|c|c|c|c|c|}
\hline total assets scale (Billion yuan) & $\leq 10$ & $(10,20]$ & $(20,30]$ & $(30,40]$ & $(40,50]$ & $>50$ \\
\hline Number of enterprises & 58 & 43 & 7 & 6 & 2 & 4 \\
\hline Main business cost (Billion yuan) & $\leq 2$ & $(2,5]$ & $(5,8]$ & $(8,12]$ & $(12,15]$ & $>15$ \\
\hline Number of enterprises & 8 & 41 & 17 & 22 & 7 & 25 \\
\hline Total assets turnover & $\leq 30$ & $(30,40]$ & $(40,50]$ & $(50,60]$ & $(60,70]$ & $>70$ \\
\hline Number of enterprises & 25 & 31 & 17 & 20 & 17 & 10 \\
\hline
\end{tabular}

Table 2. Statistic distribution for the original data of output index.

\begin{tabular}{|c|c|c|c|c|c|c|}
\hline Rate of return on net assets (\%) & $\leq 0$ & $(0,5]$ & $(5,10]$ & $(10,15]$ & $(15,20]$ & 13 \\
\hline Number of enterprises & 8 & 17 & 32 & 41 & $(20,25]$ \\
\hline $\begin{array}{c}\text { Main business income (Billion } \\
\text { yuan) }\end{array}$ & $\leq 5$ & $(5,10]$ & $(10,15]$ & $15,20]$ & 12 & 9 \\
\hline $\begin{array}{c}\text { Number of enterprises } \\
\text { Asset liability ratio (\%) }\end{array}$ & 37 & 32 & 15 & $(0.3,0.4]$ & $(0.4,0.5]$ & $>0.5$ \\
\hline Number of enterprises & 18 & 48 & 21 & 8 & 6 & 19 \\
\hline
\end{tabular}

Table 3. The overall situation of small and medium enterprise financing efficiency.

\begin{tabular}{|c|c|c|c|}
\hline \multirow{2}{*}{ Type } & Effective or Not & Number of Enterprises & Percentage \\
\hline \hline \multirow{2}{*}{ Comprehensive efficiency } & Yes & 15 & $12.5 \%$ \\
\cline { 2 - 4 } & No & 105 & $87.5 \%$ \\
\hline \multirow{2}{*}{ Pure technical efficiency } & Yes & 21 & $17.5 \%$ \\
\cline { 2 - 4 } & No & 99 & $82.5 \%$ \\
\hline
\end{tabular}

the experience of the DEA model application. Afterwards, the input indexes we used are (1) Total assets of an enterprise, (2) Main business cost, (3) Asset liability ratio, on the other hand, the output indexes refer to (1) Rate of return on net assets, (2) Main business income, (3) Total assets turnover. Next, we illustrate the Statistic distribution for the original data of input index in Table $\mathbf{1 .}$

Similar to Table 1, we provide statistic distribution for the original data of output index in Table 2.

According to the above two tables, using the proposed improved DEA model, the financing efficiency of our dataset is listed as follows in Table $\mathbf{3}$.

Afterwards, we utilize the $C^{2} R$ model to estimate the distribution of comprehensive technology efficiency (shown in Fig. 1).

Next, in Fig. (2), we provide the distribution of pure technical efficiency under $C^{2} G S^{2}$ model using our proposed DEA method.

To compare the small and medium enterprise financing efficiency in different years, we show how the financing efficiency with the time varying in Fig. (3).
Integrating all the experimental results together, some rules in the small and medium-sized enterprise financing efficiency in China can be obtained, and some conclusions are drawn as the following aspects.

\begin{tabular}{|c|c|c|c|}
\hline $\begin{array}{l}\text { 口 }(0.98,1] \\
\square(0.92,0.94]\end{array}$ & $\begin{array}{l}=(0.96,0.98] \\
\\
\square(0.9,0.92]\end{array}$ & $\begin{array}{l}\square(0.94,0.96 \\
\square(0,0.9]\end{array}$ & \\
\hline \multicolumn{4}{|c|}{10} \\
\hline \multicolumn{4}{|c|}{17} \\
\hline \multicolumn{4}{|c|}{18} \\
\hline & & 27 & \\
\hline & & & 32 \\
\hline \multicolumn{4}{|c|}{16} \\
\hline
\end{tabular}

Dis tribution of compre he nsive technology efficiency

Fig. (1). Distribution of comprehensive technology efficiency using the proposed model. 


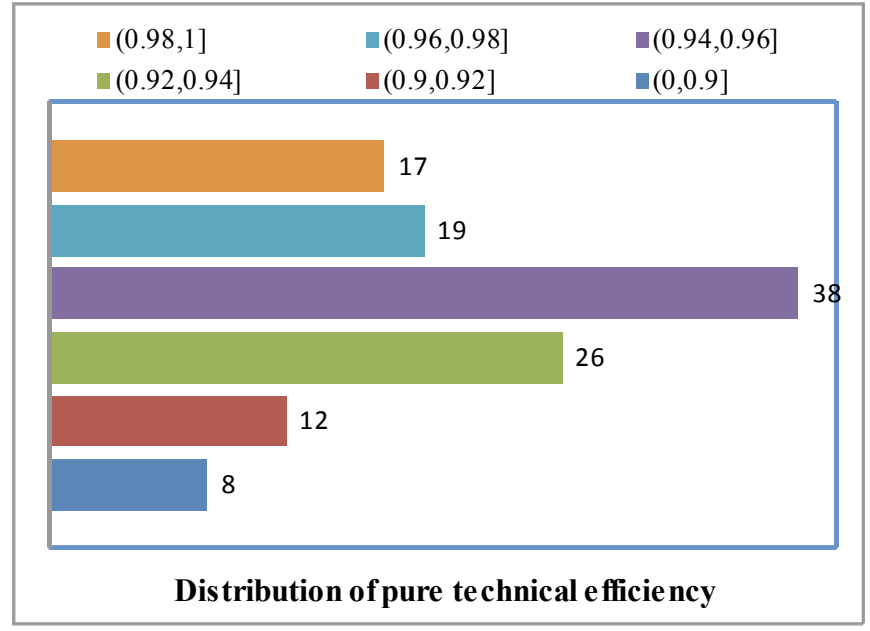

Fig. (2). Distribution of pure technology efficiency using the proposed model.

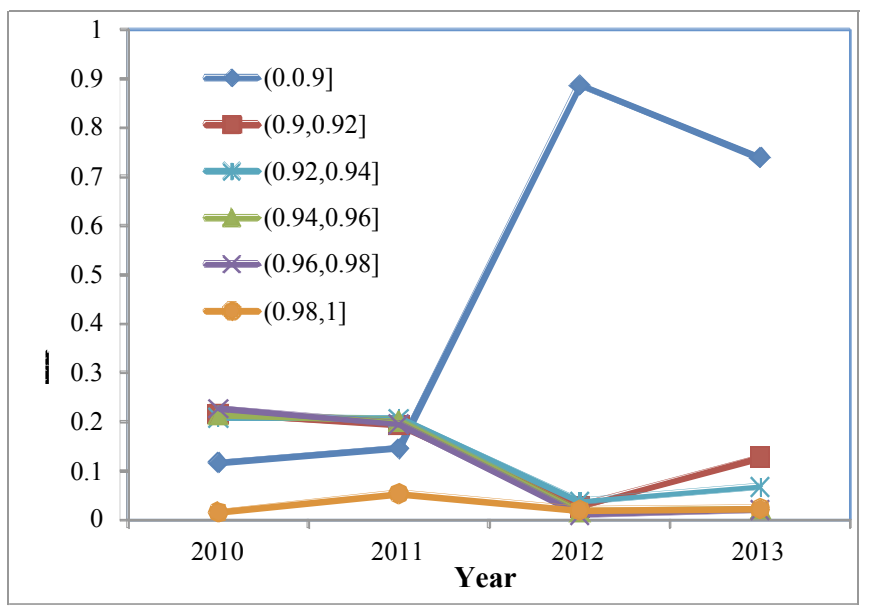

Fig. (3). Financing efficiency with the time varying.

(1) For the small and medium-sized enterprises in China, there are only a few of enterprises which can achieve the DEA effective degree, and the overall financing efficiency of small and medium-sized enterprise is not high.

(2) In China, overall financing efficiency of the small and medium-sized enterprises decline in recent years.

(3) In the small and medium-sized enterprise, the financing efficiency of the enterprises that produce common consumer products is significantly higher than other industries, and more stable.

\section{CONCLUSION}

In this paper, we present an improved DEA model based on stepwise regression. To tackle the limitations in traditional DEA model, we improve the DEA model utilizing the stepwise regression technology that can automatically choose variables for the DEA model. Finally, in the experiment, we collect 120 small and medium enterprises of China in 2010-2013 to construct a dataset. After investigating the experimental results, we provide some suggestions to enhance the small and medium-sized enterprise financing efficiency for governments.

\section{CONFLICT OF INTEREST}

The author confirms that this article content has no conflict of interest.

\section{ACKNOWLEDGEMENTS}

Declared none.

\section{REFERENCES}

[1] H. Li, and F. Shi, "Research on logistics financing efficiency for small and medium enterprises based on fuzzy comprehensive evaluation", In: Proceedings of the 2010 International Conference of Logistics Engineering and Management, vol. 387, pp. 40144021, 2010.

[2] N. Yang, "Evaluation of the financing efficiency for small and medium high-tech enterprises in Henan Province", In: Proceedings - 2010 2nd IEEE International Conference on Information and Financial Engineering, 2010, pp. 323-327.

[3] Y. Yang, K. Xu, Y. Kang, "A study on financing efficiency of high-tech small and medium-sized enterprises in Beijing”, In: 2009 International Conference on Management Science and Engineering, 2009, pp. 1843-1847.

[4] Q. Zhang, "The comparison of financing efficiency between small and medium-sized enterprises and the research of financing channel management", Advances in Intelligent and Soft Computing, vol. 106, pp. 241-247, 2011.

[5] A.R. Gopal, G. Leventis, A. Phadke, du Can Stephane de la Rue, "Self-financed efficiency incentives: case study of Mexico", Energy Efficiency, vol. 7, no. 5, pp. 865-877, 2014.

[6] N. Lin, and X. Wen, "Financing and Investment Efficiency, Information Quality, and Accounting Biases", Management Science, vol. 60 , no. 9 , pp. 2308-2323, 2014.

[7] C.M.Dragos, and S.L. Dragos, "Scientific productivity versus efficiency of R\&D financing: bibliometric analysis of African countries", Current Science, vol. 106, no. 7, pp. 942-945, 2014.

[8] D.A. Silva, G.I. Alves, S.G. de Mattos Neto Paulo, and T. A. E. Ferreira, "Measurement of Fitness Function efficiency using Data Envelopment Analysis", vol. 41, no. 16, pp. 7147-7160, 2014.

[9] Y. Han, Z. Geng, and Q. Liu, "Energy efficiency evaluation based on data envelopment analysis integrated analytic hierarchy process in ethylene production", Chinese Journal of Chemical Engineering, vol. 22, no. 11-12, pp. 1279-1284, 2014.

[10] T. Amin, N. Maryam, M. Arab, F. Freshteh, G. Roya, "Hospitals productivity measurement using data envelopment analysis technique," Iranian Journal of Public Health, vol. 43, no. 11, pp. 1576$1581,2014$.

[11] T. Heinz, R.R. Sinkovics, and P. Grigory, "Towards a consolidation of worldwide journal rankings - A classification using random forests and aggregate rating via data envelopment analysis", Omega-international Journal of Management Science, vol. 51, pp. 11-23, 2015.

[12] J. Vipul, A. Kumar, S. Kumar, and C. Chandra, "Weight restrictions in Data Envelopment Analysis: A comprehensive Genetic Algorithm based approach for incorporating value judgments", Expert Systems with Applications, vol. 42, no. 3, pp. 1503-1512, 2015.

[13] K.D. Kaveh, T. Madjid, and H.S. Elham, "A data envelopment analysis model with interval data and undesirable output for combined cycle power plant performance assessment", Expert Systems with Applications, vol. 42, no. 2, pp. 760-773, 2015.

[14] F. Lei, and H. Li, "Cost efficiency in data envelopment analysis under the law of one price", European Journal of Operational Research, vol. 240, no. 2, pp. 488-492, 2015.

[15] F. Pelone, D. S. Kringos, R. Alessandro, A. Monica, S. Chiara, and R. Walter, "Primary Care Efficiency Measurement Using Data Envelopment Analysis: A Systematic Review", Journal of Medical Systems, vol. 39, no. 1. 2015.

[16] R.D. Banker, K. Kotarac, and L. Neralic, "Sensitivity and stability in stochastic data envelopment analysis", Journal of the Operational Research Society, vol. 66, no. 1, pp. 134-147, 2015.

[17] A.K. Ustun, and B. Gulay, "Performance evaluation of Turkish disaster relief management system in 1999 earthquakes using data envelopment analysis", Natural Hazards, vol. 75, no. 2, pp. 1977 1996, 2015. 
[18] H. Omrani, R.G.Beiragh, and S.S. Kaleibari, "Performance assessment of Iranian electricity distribution companies by an integrated cooperative game data envelopment analysis principal component analysis approach", International Journal of Electrical Power \& Energy Systems, vol. 64, pp. 617-625, 2015.

[19] Y. Han, and Z. Geng, "Energy Efficiency Hierarchy Evaluation Based on Data Envelopment Analysis and its Application in a Petrochemical Process", Chemical Engineering \& Technology, vol. 37, no. 12, pp. 2085-2095, 2014.

[20] B.A. Reza, and E. Ali, "Influential DMUs and outlier detection in data envelopment analysis with an application to health care", $\mathrm{An}$ nals of Operations Research, vol. 223, no. 1, pp. 95-108, 2014.

[21] K. Mohsen, A. Shabani, and S.R. Farzipoor, "A new look at measuring sustainability of industrial parks: a two-stage data envelopment analysis approach", vol. 16, no. 8, pp. 1577-1596, 2014.
[22] K. Leila, A. Alireza, Matin, and R. Kazemi, "Marginal rates of substitution in the presence of non-discretionary factors: A data envelopment analysis approach", Measurement, vol. 58, pp. 409-415, 2014.

[23] M. Yang, Y. Li, Y. Chen, and L. Liang, "An equilibrium efficiency frontier data envelopment analysis approach for evaluating decision-making units with fixed-sum outputs", European Journal of Operational Research, vol. 239, no. 2, pp. 479-489, 2014.

[24] A. Jalah-Heravi, and Z. Garkani-Nejad, "Prediction of electrophoretic mobilities of alkyl- and alkenylpyridines in capillary electrophoresis using artificial neural networks", Journal of Chromatography $A$, vol. 971, no. 1-2, pp. 207-215, 2002.

Received: June 10, 2015

Revised: July 29, 2015

Accepted: August 15, 2015

(C) Yuan Feng; Licensee Bentham Open.

This is an open access article licensed under the terms of the (https://creativecommons.org/licenses/by/4.0/legalcode), which permits unrestricted, noncommercial use, distribution and reproduction in any medium, provided the work is properly cited. 